Journal of

Property

Finance

7,3

38

\section{Indemnities for long-term price risk in the UK housing market}

\author{
R. Guy Thomas \\ Actuarial Science Group, University of Kent at Canterbury, \\ Canterbury, UK
}

\section{Introduction}

For many individuals in the UK, buying a house is the largest financial risk they will ever take. In any other market the idea of unsophisticated investors financing 90 per cent or more of the purchase price of an asset by borrowing would be regarded as absurdly imprudent. But housing has been (seen as) different: the extended post-war increase in nominal house prices, combined with financial liberalization and increased competition to lend, has led to high financial gearing being regarded as normal practice in the housing market.

In the last few years, however, participants in the housing market in the UK have experienced an unpleasant shock: the post-war pattern of ever-increasing nominal prices has been broken. Widespread falls in property prices have created much hardship for house owners who bought on borrowed money at the height of the boom. Over the last few years, these house owners have discovered that the high financial gearing underpinning their investment in housing is a distinctly double-edged sword. Many such house owners, while they may still desire the security of tenure which ownership confers, are probably now less enthusiastic about assuming highly geared exposure to price variations. The purpose of this paper, therefore, is to propose a means by which individual house buyers might be protected against future falls in prices.

The rest of this paper is organized as follows. The next section sets out some salient differences between the markets for housing and for other assets, followed by a section which considers what type of indemnity against falls in house prices it would be feasible to offer house buyers.

There then follows the main proposal in this paper, the establishment of long term futures markets related to indices of housing assets, and the development of retail indemnity products hedged by positions in this futures market. There are then further comments on this proposal, and a section which suggests some of the possible users of these futures. The penultimate section outlines further research which is likely to be required before the proposals in this paper can be put into practice. The final section summarizes and concludes the paper.

Differences between the markets for housing and for other assets There are a number of important differences between housing assets and the financial assets (and commodities) which are already traded in futures markets. 
M ost financial and commodity markets are dominated by professional investors and traders. They are able to take a dispassionate view of price prospects; they are as willing to sell the asset as they are to buy; they are able to change their minds within very short timescales; and having decided to sell or to buy, they can implement those decisions very quickly. Such professional investors are almost entirely absent from the housing market, which consists of millions of small-scale participants who are putting most of their wealth at risk in the

Price risk in the UK housing market trading process. M ost of these participants are not able to learn from experience to any significant degree, because they make only a limited number of transactions over a lifetime. The prices at which transactions take place are not published, so that it is always difficult to assess the state of the market.

The absence of well-informed, professional investors from the housing market seems likely to be an obstacle to rational pricing. One of the advantages of a futures market is that it would provide a convenient way for professional investors to participate in the housing market, without the administrative complications associated with actual ownership of property.

The housing market is also complicated by other emotions largely absent from financial markets: a house is not just a speculative asset but a home. The result is that while the owner of a house very often sees it as "an investment" as well as a home, it is difficult to treat the asset in the same dispassionate way as other assets. To some extent, these emotions may arise from a confusion between two aspects of home ownership: security of tenure, and exposure to price changes. The first is probably desirable; the second is a double-edged sword.

The housing market in England and Wales has an unusual (and muchcriticized) system of trading involving non-binding forward sales and purchases. In times of rapidly changing prices, this system encourages buyers or sellers to renege on the non-binding agreements. T his behaviour is popularly referred to as "gazumping" for buyers or "gazundering" for sellers.

One of the reasons for the system of non-binding forward sales is that all transactions in the housing market are on a "matched bargain" basis: a house can generally be sold only if and when a buyer who wishes to live in the house is found. There are no organizations fulfilling a market-making role, and almost no professional dealers or speculators. These features mean that the market is relatively illiquid. They may also have the effect of making prices "sticky downwards": rather than prices falling to the level which clears the market, the volume of transactions tends to fall. This may be because individuals selling their homes generally lack the expertise and dispassionate judgement of professional traders, and are therefore reluctant to recognize falls in value. "Sticky downwards" prices have the unfortunate result that when price declines finally do occur, a large number of transactions are likely to have been made at close to peak prices.

Possibly as a consequence of the absence of professional investors in the market, changes in house prices exhibit high autocorrelation; this has been a consistent finding in studies from several countries, including the USA, Norway 
Journal of

Property

Finance

7,3

40

and Japan (Case and Shiller, 1989; Ito and Hirono, 1993; Nordvik, 1995). Price expectations appear to be formed through an extrapolation of past trends rather than through any process based on economic fundamentals or demographic trends (Nordvik, 1995). Price trends therefore persist to a greater extent than in financial markets, in which prices are typically observed to be "random walks", at least over short intervals.

Speculative markets in general are subject to periodic booms and busts. But there are reasons for regarding such cyclical behaviour as particularly damaging in the case of housing. Most participants in the housing market are highly geared and have a very high proportion of their wealth invested in housing. The impact of cyclical behaviour may therefore be more pervasive than booms and busts in other markets. A Iso, the dual role of housing as shelter and as a form of investment means that booms and busts may have more direct and extensive social costs than in other markets.

\section{Indemnities for property prices}

W hat could be done to mitigate the undesirable features of the UK housing market which have been outlined above? The proposal of this paper is that arrangements should be made for the financial risk of house ownership to be passed on by the owner to an institution more capable of sustaining the risk. In other words, at the same time as taking out a mortgage, the house owner would buy a policy providing an indemnity against falls in market value. From the house owner's viewpoint, the ideal policy would pay out any shortfall in the resale price as compared with the original purchase price, on the sale of the house at any time during the term of the mortgage. Effectively this would be a put option on the value of the house. The policy could be paid for either by recurrent annual premiums or by a single premium; the latter would probably be more suitable, as it would avoid the problem of "selective lapses" (that is, the tendency of policyholders to discontinue premium payments when house prices have risen).

It would not be viable to provide an indemnity against falls in value of a specific house, for two reasons. First, there is the problem of moral hazard: an indemnity against falls in the value of a particular house would be a disincentive to the policyholder to maintain the house, and to achieve the best possible price on resale. Second, there is the problem of price discovery: professional valuation of a single house is a subjective matter; actual sales are infrequent; and the price agreed would bevulnerable to manipulation motivated by the existence of the insurance policy. T hese problems could be alleviated by the use of policies with a percentage deductible, but the problem would remain to some extent. However, it should be viable to offer indemnities against a fall in house prices in general, as measured by national or regional indices of house prices, rather than against a fall in the price of a particular house. Home owners who had purchased such an indemnity would have an incentive to sell in a depressed housing market, although the extent of this incentive would be mitigated by any deductible applied to the policy. In effect, the indemnity gives 
them a put option on a price index. However, this option differs from most financial options in that it has high costs of exercise: it can be exercised only by the (costly, time-consuming, disruptive) process of selling one's house. In pricing the put option, allowance would need to be made for the extent to which the financial and social costs of moving house inhibit exercise of the option. We might call this factor "customer inertia". (T he pricing problem has some similarity to the pricing of securitized mortgage products in the USA, for which

Price risk in the UK housing market the anticipated customer inertia factor is the failure of some mortgage customers to remortgage in response to falls in interest rates.)

It could be argued that the pricing problem would be simplified if house owners did not have to sell their houses in order to collect a payout, i.e. the terms of the policy should be that it will pay out at the end of a fixed term irrespective of whether the house is sold. However, this approach would probably be less attractive to insurers, and so such policy terms seems less likely to be successful in practice than terms which pay out only on the sale of the house.

Colloquially, such a policy might well be referred to as a "house price insurance". From the view point of the policyholder, it is indeed analogous to an insurance policy, and previous authors (Gemmill, 1990; Shiller, 1993a), have used the term "insurance". How ever, from the viewpoint of an institution selling such policies, the portfolio would be fundamentally different from conventional insurances such as life insurance, motor insurance etc. in that there would not be a pooling of independent risks. The risks for different policies would be highly correlated, and so there would be little or no proportionate reduction in the overall risk of the portfolio as the number of policies increased. What is being proposed is not a pooling of risk but a transfer of risk away from individuals to institutions which are willing to bear the risk - at a price. It is therefore more appropriate to refer to indemnities rather than the insurance policies. This terminology is also consistent with that already used for mortgage indemnity guarantee policies, which offer a benefit somew hat similar to that proposed here, but in more restricted circumstances: that is, they provide an indemnity for any shortfall between the sale price achieved and the outstanding mortgage loan in the event of the borrower's default.

How should such indemnities be priced? The macroeconomic risk against which the policy protects would affect all contemporaneous policyholders in a similar manner, so investigation of policyholders' individual circumstances is largely irrelevant. What is needed is a mechanism for discovering the price which attracts sufficient risk capital to provide the quantity of indemnity cover for which there is demand. Thus a market in which the house price risk can be traded is required. The next section introduces proposals for such a market.

\section{Perpetual claims and perpetual futures}

A market for the transfer of house price risk could be created by establishing a long-term futures market related to an index of housing assets. This would enable the institutions providing the retail indemnity products to lay off the price risk in the futures market. This would probably be done by buying put 
Journal of

Property

Finance

7,3

42

options on the index - that is, the right, but not the obligation, to "sell" the index at a future date at a predetermined "strike price". (Note that this would allow the financial institution to hedge the price risk, but it would retain the risk associated with the unknown extent of the "customer inertia" factor referred to above.)

The price at which indemnity was offered would be determined largely by the price at which the risk could be hedged. The risk would ultimately be borne by traders in the futures market: the retail financial institution would just be collecting the margin between the price of the indemnity policy and the wholesale price of house price risk. The financial institutions most likely to be involved are probably those which have an interest in a vigorous housing market. M ortgage lenders are the most obvious candidates, although third parties such as conventional insurance companies might well have a role to play.

Our proposal is different to the futures on the Halifax Price Index proposed by Gemmill (1990) in that our proposal is for long-term futures. Gemmill envisaged futures with a maximum duration of two years: the main purpose was to provide a mechanism for indemnities against short-term changes in value, thus alleviating the problem of gazumping, which was of contemporary concern in the boom conditions of the late 1980s. Our present objective is to create a means of mitigating long-term changes in value. Note that holding and periodically rolling over a position in a short-term derivative would not achieve this objective reliably. The high autocorrelation of changes in house prices means that price changes over short terms are to some extent predictable, and so a short-term future would anticipate these changes, and therefore be of little use for hedging purposes.

The somew hat imprecise notion of long-term futures gives rise to the following questions. How long is long-term? W hat range of contract terms do we need? If we have a wide range of terms, will there be sufficient liquidity in all the terms? These questions can be side-stepped by initially diverting attention away from finite terms and considering instead contracts on perpetual streams of income, as proposed by Shiller (1993a; 1993b).

Shiller suggests two new types of financial instrument, perpetual claims and perpetual futures. The perpetual claim is the simpler concept, but the perpetual future might be more convenient for hedging purposes. The perpetual claim is a contract which pays a yield proportional to an index of income from housing assets, in perpetuity. It therefore has broadly the same financial implications as freehold ownership of housing assets. Perpetual claims effectively price a future cash flow, thus creating an asset value for the index of income. A perpetual claim differs from a conventional future in that its value at inception is not zero: to longs (those who have "bought" the contract), the perpetual claim is an asset, while to shorts (those who have "sold" the contract), a perpetual claim is a liability.

A $n$ alternative type of contract, probably more useful for the purposes of hedging, is the perpetual future. Perpetual futures are similar to futures of finite 
term, in particular they have zero value at the time at which they are entered into. How ever, they differ from conventional futures in that they have no maturity date. Instead of a delivery of the underlying asset on maturity, the periodic resettlement (marking to market) includes an element relating to the comparative return on an alternative asset. A perpetual future is then defined as a contract (Shiller, 1993a, p. 42) under which the settlement from shorts to longs at timet is:

$$
s_{t}=\left(f_{t}-f_{t-1}\right)+\left(d_{t}-r_{t-1} f_{t-1}\right)
$$

where $s_{t}$ is the settlement; $f_{t}$ and $f_{t-1}$ are the futures prices at time $t$ and $t-1$ respectively; $r_{t-1}$ is the return from $t-1$ to $t$ on an alternative asset (e.g. risk-free bonds); and $d_{t}$ is the index of income received at time $t$ on a perpetual claim, which is defined as above.

The first term above $\left(f_{t}-f_{t-1}\right)$ is identical to the periodic "marking to market" which is carried out for conventional futures of finite term: it represents the change in the market price of the perpetual future between time $t-1$ and time $t$. The second term $\left(d_{t}-r_{t-1} f_{t-1}\right)$ represents the difference between the income from housing assets, and the income from an alternative asset. Note that $d_{t}$ will be zero on every day except when the income on the index is deemed to be payable. Thus the perpetual futures price will fall on income payment days, in the same way as (for example) share prices fall on ex-dividend days.

This second term appears unfamiliar, but a little thought shows that the theoretical pricing of conventional futures also depends on alternative asset. The argument underpinning theoretical pricing of conventional futures invariably makes reference to the risk-free interest rate, on which the deviation of the futures price from the cash price depends. The price may therefore be said to depend on the return on an alternative asset, namely a risk-free deposit.

A lthough we have mentioned risk-free bonds as a possible alternative asset in the pricing formula, this was only an example, not a specific requirement. It can be show $n$ that if the alternative asset enjoys a liquid market, and zero transaction costs, the particular choice of alternative asset has no effect on the price of $f_{t}$ of the perpetual future (Shiller,1993a, A ppendix 1, ch. 3). In practice, risk-free bonds (e.g. govemment stock) would probably come closest to fulfilling the "liquid market and zero transaction costs" criteria.

A nother way of looking at the second term $\left(d_{t}-r_{t-1} f_{t-1}\right)$ in the pricing formula is to see it as a swap of one income flow (the income represented by the index) for another income flow (the income from holding the alter native asset). This means that while the choice of alternative asset has no effect on $f_{t}$ under the assumptions above, the choice is in practice not irrel evant, because it determines the return for which hedgers swap the income represented by the index. Risk-free index-linked bonds (e.g. index-linked gilts in the UK) might be a particularly appropriate choice, since this would allow real, rather than nominal,values to be hedged.

A ppendix 1 shows an illustrative example of the pricing mechanism outlined above. 
Journal of

Property

Finance

7,3

44
A ppendix 2 explains why the price $f_{t}$ of a perpetual future is expected to tend to track the market value of the corresponding perpetual claim. W hile the prices of the two instruments are expected to be similar, the advantage of the perpetual future for hedging purposes is that no payment is needed when the contract begins (apart from some small margin payment as required by the futures exchange for prudential reasons). M oney changes hands only to the extent required by the periodic marking to market of the open contract.

Note that it is not necessary for any institution to create the perpetual claim, by guaranteeing to make payments of income on the index in perpetuity. It is sufficient that a futures exchange establishes and enforces daily mark-tomarket and margining requirements for the perpetual future, and that an index of income on a notional perpetual claim is available. Provided that the market has confidence in these arrangements, the perpetual claim need not be traded, and can remain entirely notional.

A t present the broad-based indices of income on perpetual claims on housing assets which would be required for the pricing of perpetual futures are not available. How ever, the advent of housing investment trusts, as proposed in the housing white paper published by the UK government in June 1995 (Department of the Environment, 1995) will give rise to observable, broadlybased income streams from letting residential property. The rental streams for different quoted companies would be combined to form an income index, in a similar manner to existing yield indices for income from other assets (e.g. quoted shares). In one respect an index of rental income is less problematic than existing indices of capital values: the rent on any given house is observed regularly, but the capital value of any given house is not. (A nother possible source of index data is the Joseph Rowntree Index of Private Rents and Y ields (Rhodes and Kemp, 1996).)

In view of the differences between house price movements in different regions of the UK (Drake, 1995) which have been quite marked in some periods, it would be desirable to have separate perpetual futures contracts for different regions (e.g. South-east England, Scotland, Northern Ireland, etc.). A further development would be to have separate indices for different types of properties (e.g. apartments, terraced, detached) in each area. Diversification across the regions and across types of houses could reduce the overall risk for insurers and participants in the futures markets. It would be possible for traders to take positions in the relative movement of prices in different regions and in different types of houses. However, it seems unlikely that adequate liquidity could be generated in such an array of contracts in the early stages of a perpetual futures market: they would be more likely to be added at a later stage, when a notional contract had already become established.

Once a perpetual futures market had been set up, it would not be necessary to have an array of contracts of shorter duration. Hedging of commitments for finite terms could be achieved by a short position in the perpetual future combined with a forward contract to buy a perpetual future at the end of the required finite term. For example, the price risk of owning a house over the 
25-year duration of a mortgage could be hedged by a short position in the perpetual future and a forward contract to buy the perpetual future at the end of 25 years. The forward contract would probably be written on an offexchange (over the counter) basis by a financial institution. House owners

Price risk in the UK housing market might well prefer to buy a policy of shorter term than their outstanding mortgage; if so, this could be hedged in a similar manner.

\section{Other comments}

Comparison of perpetual claims with rental values

The concept of a perpetual claim on a stream of rents may be related to the more familiar concept of rental value (that is, the income received from a property) by assuming a rental growth g per annum and a risk-adjusted discount rate $r$ per annum. Then the price of the perpetual claim, say $P$, is related to the rental value, say $R$ as follows:

$$
P=R\left(\frac{1+g}{1+r}\right)+\left(\frac{1+g}{1+r}\right)^{2}+\ldots \approx \frac{R}{r-g} .
$$

That is, the perpetual claim is equal to a perpetuity of the rental value discounted at the real risk-adjusted rate of discount, where "real" implies allowance for the growth in rental value.

Comparison with guarantees on equity investment products

A s noted above, many people in the UK have most of their wealth invested in housing; certainly this is a more typical situation than to have most of one's wealth invested in the stock market. It is therefore ironic that equity investment products with "guarantees" based on the use of derivatives are already available, but there are no similar products for property. The reason is probably that derivative markets are well developed for equities, but are almost unheard of for property.

Effect of house price futures on general price levels

Would the existence of a futures market have any effect on the general level of house prices? To the extent that the futures market can be used to reduce the risk which holding housing assets entails, one would expect prices to increase as people become more willing to hold housing assets. Such an increase should not be seen as undesirable; it would reflect a genuine increase in the wealth of society resulting from more effective arrangements for risk management.

However, the introduction of a futures market could also draw in a new class of professional investors, whose motives would differ from those of owneroccupiers. It is possible that speculative forces unleashed by the new market could result in more volatile prices. Theoretical models of the effect of the introduction of a futures market on volatility in the cash market are inconclusive on this point, because small changes in the model result in opposite conclusions (Chari et al., 1990). Empirical studies have been carried 
Journal of

Property

Finance

7,3

46

out for many futures markets, but these are also inconclusive overall (Sutcliffe, 1993).

Possible problems

One concern is whether the indemnity policies proposed here could be made available at a price which house buyers find acceptable. We will not be able to calculate actual premiums until further data-based investigations (suggested later in this paper) have been carried out. How ever, we can say that if the futures price was such as to imply falling property values in future years, or if the expected volatility of the house price index was high, then the derivatives which insurers would need to buy or replicate in order to hedge indemnity policies on house prices would be expensive, and this high cost would be passed on to house buyers in the price of retail indemnity policies. But in that case, the high price of the policies would act as a warning to house buyers that professional investors considered housing overpriced (or prone to high price volatility). Bearing in mind that it would be reasonable for individuals to be more risk averse than large financial institutions, house buyers would be well advised to heed this warning. Thus creation of the futures market can be seen as a way of increasing the influence of expert judgment in the housing market, thereby facilitating the setting of prices in a more rational manner.

A nother concern with the proposals in this paper is default risk in the futures market. In order to minimise this risk, careful attention would need to be given to mark to market rules (i.e. paper losses or gains on long-term contracts would be payable in cash on a regular basis). It would be desirable for the market to be set up under the auspices of a well-established and respected futures exchange.

Given the novelty of perpetual futures and the lack of an easily observable corresponding "cash" price (i.e. the perpetual claim), there will be much greater uncertainty about the initial market price than with conventional limited-term futures (for which prices are constrained by no-arbitrage conditions relative to an easily observable cash price). The uncertainty is rather similar to that which pertains to the appropriate offer price for the flotation of a company on the Stock Exchange, and some of the procedures used in underwriting such issues may be adopted here. For example, publicity programmes by underwriters (or in this case, the futures exchange) and assessment of initial interest by the underw riters help to gauge the appropriate initial price (Shiller, 1993b).

A more general concern is that a market in housing futures may not be a natural market in the sense of having a large number of market participants who have "natural" reasons to buy or to sell. T he natural sellers are the insurance companies or other financial institutions which have portfolios of indemnity policies to hedge. Some other possible participants are discussed in the next section, but most appear to be more likely to be sellers than buyers.

However, securitized investments in residential property should be of interest to institutional investors as an additional asset class for long term investment. Modern portfolio theory suggests that it is generally advantageous for investors to diversify their investments across countries and across the various 
asset classes such as equities, bonds, etc.; recent studies have confirmed that benefits can be obtained by adding further classes of investment (eg. commodities) to a portfolio (A nkrim and Hensel, 1993; Shimko and Masters, 1994; Strongin and Cohen, 1994). Traditionally, residential property has been

Price risk in the UK housing market seen as unsuitable for institutional portfolios, largely because of the practical complications involved in managing a large number of individual tenancies. Securitized investments such as perpetual claims and perpetual futures avoid these complications, and should therefore be a practical long-term holding for institutional investors. Perpetual instruments are also much more suitable for long-term investors than conventional derivatives with relatively short fixed terms, because the price risk and transaction costs of rollovers are eliminated.

It is also interesting to note that the housing market in the UK has been estimated to have a capital value of around $f 1,000 \mathrm{bn}$ (Collett, 1996), which make it the largest capital market in the UK. Thus currently we have the very strange situation that institutional investors are ignoring the asset class that is the largest by value available to them in the UK.

In addition to long term institutional investors, a successful derivatives contract also depends on speculators to supply short-term liquidity. In order to attract speculators some form of incentive may be necessary, for example, a fiscal incentive. One possibility could be to exempt gains on futures trading from all taxation. This would be analogous to the capital gains tax exemption currently enjoyed by owner occupiers, and the similar exemption which has been proposed for housing investment trusts (HM SO, 1995).

It is unlikely that the indemnity policies outlined in this article can become established without the development of the corresponding futures market. Unfortunately this could take several years, and a previous attempt following a proposal by Miller (1989) was not successful. A lthough the contract was dogged by a regulatory scandal (Futures and Options World, 1991) the more fundamental reason for its failure was probably the novelty for institutional investors of the idea of any sort of residential property investment. Residential property has long been neglected by institutional investors, because of the lack of liquidity and tenure problems in the cash market. They were therefore not particularly interested in the facility to take positions in future prices.

However, if institutions were underwriting the retail indemnity products described above, they would have a clear need to hedge these policies; futures on indices of housing assets are the obvious means of achieving this.

The interdependence of demand for futures on housing assets and the proposed retail indemnity policies could be seen as a "Catch 22": neither market is likely to prosper until the other one has done so. Some external stimulus may be needed to create conditions favourable to the establishment of one or other of the markets. One possibility is some fiscal concession which makes the proposed futures more attractive to institutions. A nother possibility is that increasing acceptance and usage of derivatives on property indices generally may lead to derivatives on residential property being seen as a natural extension of other markets. In this respect, it is encouraging to note the recent 
Journal of

Property

Finance

7,3

48 proposals by a group of UK institutions to establish a Real Estate Index Market (REIM). (This will be a market for the trading of derivatives linked to the Investment Property Databank (IPD) indices of returns on various categories of property; residential property is not included (Financial T imes, 1996).)

\section{Other possible users of futures on indices of housing assets}

A part from house owners wishing to protect themselves (through intermediary financial institutions) against a fall in the general level of house prices, there are other possible users of futures on indices of housing assets (Gemmill, 1990, pp. 201-2). For example, builders may wish to hedge profits on houses due to be completed in several months' time. This may mitigate boom-bust effects arising from the time lag between new housing starts and the marketing of finished houses.

Expatriates could use futures to keep a stake in the UK property market in preparation for their return, as could young people who are not yet ready to buy a house but fear being left behind by a property price boom. A person holding two houses, with a bridging loan, could hedge the price of the house he or she is trying to sell.

From the viewpoint of financial institutions, a conventional mortgage indemnity guarantee policy can be seen as a more restricted version of the indemnity contracts proposed here, with payout limited to particular circumstances (borrower default with sale proceeds less than the outstanding loan). Futures on indices of housing assets could be of value in hedging and pricing these policies, assuming that suitable allowance was also made for other factors which affect the probability of borrower default.

The futures contract could also facilitate the operation of "chain-breaking" services (more accurately, chain-mending): the chain-mender could offset its price risk by an appropriate futures position. To put this idea in another way, estate agents could act as principals rather than agents. They would, of course, need to be adequately capitalized to fulfil this role (although the price risk on a nationally diversified hedged portfolio should be minimal, so that the capital requirements need not be as onerous as they might at first appear).

\section{F urther research}

A substantial amount of further work is likely to be necessary before the above proposals can be put into practice. Further work is planned in two main areas: the theoretical pricing of forward contracts and options on perpetual futures; and models for changes over time in the rental income earned from housing assets.

With regard to theoretical pricing of forwards and options, it may be possible to adapt some of the methodology underlying the pricing of forwards and options on other assets.

However, this methodology relies on an arbitrage-free condition linking prices in the spot market and the forward contract on its maturity date. In addition to no-arbitrage conditions, conventional methods of options pricing 
depend heavily on the assumption that price changes are random walks, which allows the variance of price changes to bescaled up or down in proportion to the finite term of the contract concerned. It is not immediately obvious how this framew ork can beadapted to the case of perpetual futures on indices of housing assets, which would have no finite term and where (because of extrapolative expectations) the price of the underlying asset is not likely to be a random walk; some alternative approach seems likely to be necessary. In the absence of noarbitrage arguments and random walks, it may be worth seeking inspiration in some of the earlier attempts at option pricing (for example, Boness, 1964; Samuelson, 1965; Sprenkle, 1964)

A s regards models for the changes in rental income over time, the main problem is likely to be scarcity of data. Price data for housing are generally for capital values rather than rental incomes. One starting point is previous estimates of rental incomes on assured tenancies under the Business Expansion Scheme (Best et al., 1992). Observations of the yields on housing investment trusts (Department of the Environment, 1995) and the newly established Joseph Rowntree Foundation Index of the Private Rents and Y ields (Rhodes and Kemp, 1996) may also be of assistance.

\section{Summary and conclusions}

In the last few years, the highly geared financial risk borne by most house buyers in the UK has exacted a high social cost. This paper has outlined a means by which the risk could be transferred to financial institutions which are better able to sustain the risk - at a price. This would involve financial institutions (probably, but not necessarily, mortgage lenders or insurance companies) offering retail products which indemnified house owners against falls in a general index of house prices. The policies would probably provide for a percentage deductible of the loss to be paid by the policyholder. The event triggering a claim under the indemnity policy would be the sale of the house, at any time during the owner's mortgage term, for a price less than the owner's initial purchase price. The financial institution would probably hedge this product by means of positions in a futures market in indices of housing assets. The concept of perpetual futures, which allow house price risks of any term to be hedged without the transaction costs and price risk of periodically rolling over a position, has been outlined. Further work is planned on the pricing of forward contracts on perpetual futures and options on perpetual futures, and on applications of this work to calculate appropriate prices for indemnity contracts.

A nother potential benefit of the introduction of futures on indices of housing assets is that it would provide a convenient means for professional investors to participate in the residential housing market. The entry of such investors may offset some of the problems caused by the predominance in the housing market of small-scale investors who have limited opportunity to develop market expertise, and whose judgement in the price-setting process is clouded by nonfinancial considerations. Portfolio theory suggests that institutional investors'
Price risk in the UK housing market 
Journal of

Property

Finance

7,3

50

should welcome the opportunity of another asset class into which they may conveniently diversify their assets. Perpetual futures are much more suitable for institutional investors' long-term holdings than conventional short-term derivatives, because the price risk and transaction costs of rolling over positions are eliminated.

The proposals in this paper are somewhat speculative, and many obstacles would need to be overcome before they could be put into practice. Some of these have been discussed under the heading "other comments". This paper is only the first step on what is likely to be a long journey towards practical implementation of these proposals.

The motivation for financial institutions to undertake this journey will depend on the likely interest from house buyers. For several decades up until the early 1990s, there would probably not have been much demand among house buyers for an indemnity product as described in this article, because of the perceived "one-way bet" which highly geared investment in housing promised. However, after the experience of substantial falls in the general level of house prices in recent years, and the consequential hardship, house buyers are likely to be more willing to pay for indemnities than they would have been in previous decades. It may therefore be particularly opportune for policymakers, the housing finance industry and the derivatives industry to consider the proposals outlined above.

\section{References}

A nkrim, E . and Hensel, C. (1993), "Commodities in asset al location: a real asset alternative to real estate?", Financial A nalysts Journal, May/June.

Best, R. et al. (1992), T he Future of Private Renting: Consensus and Action, Joseph Rowntree Foundation, York.

Boness, A J. (1964), "Elements of a theory of stock option value", Journal of Political Economy, Vol. 72, pp. 163-75.

Case, K.E. and Shiller, R.J. (1989), "T he efficiency of the market for single family homes", A merican Economic Review, Vol. 79, pp. 125-37.

Chari, V.V., Jagannathan, R. and Jones, L. (1990), "Price stability and futures trading in commodities", Quarterly Journal of E conomics,Vol. 105 No. 2, pp. 527-34.

Collett, A . (1996), "Property: housing as an investment", paper presented to National A ssociation of Pension Funds Investment Conference, February 1996.

Department of the Environment (1995), Our Future Homes: Opportunity, Choice, Response, Cmd 2901, HM SO, London.

Drake, L. (1995), "Testing for convergence between UK regional house prices", Regional Studies, Vol. 29, No. 4, pp. 357-65.

F inancial T imes (1996), "Investors plan property derivatives market", 5 February.

Futures and Options World (1991), "FOX on the rocks" and "F OX rocked by resignations", November, pp. 9-11.

Gemmill, G. (1990), " Futures trading and finance in the housing market", Journal of Property Finance, Vol. 1 No. 2, pp. 196-207.

Ito, T. and Hirono, K.N. (1993), "E fficiency of the Tokyo housing market", Bank of Japan M onetary and Economic Studies, Vol. 11, pp. 1-32. 
Miller, R. (1989), "Property price futures and options?", Futures and Options World, A pril, pp 75-6.

Nordvik, V. (1995), "Prices and price expectations in the market for owner occupied housing", Housing Studies, Vol. 10 No. 3, pp. 365-80.

Price risk in the

UK housing

market

Rhodes, D.J. and Kemp, P.A . (1996), Joseph Rowntree Index of Private Rents and Y ields, Centre for Housing Policy, University of York.

Samuelson, P.A . (1965), "Rational theory of warrant pricing", Industrial M anagement Review, Vol. 6, pp. 13-31.

Shiller, R.J. (1993a), M acro M arkets, Oxford University Press, Oxford.

Shiller, R.J. (1993b), "M easuring asset values for cash settlement in derivatives markets: hedonic repeated measures indices and perpetual futures", Journal of Finance, Vol. 48, pp. 911-31.

Shimko, D. and M asters, B. (1994), "Commodities - a suitable asset class", J.P. M organ, September.

Sprenkle, C.M. (1964), "Warrant prices as indicators of expectations and preferences", Yale Economic Essays, Vol. 1, pp 179-231.

Strongin, S. and Cohen, A .J. (1994), "T he case for commodities", Goldman Sachs, September.

Sutcliffe, C.M.S. (1993), Stock Index Futures, Chapman and Hall, London.

\section{A ppendix 1. Pricing of perpetual future: example}

All figures in this example are purely illustrative.

Timet - 1

Price $f_{t-1}$ of perpetual yield on index $=78$

$f_{t-1}$ represents the market's estimate of the capitalized value of the perpetual index income from an arbitrary unit of homogeneous housing assets.

Timet

Income received at time t on index of a perpetual claim on housing assets, $d_{t}=7.0$

Price $f_{t}$ of perpetual index income from one unit of housing assets $=79.5$

Return, $r_{t-1}$, on alternative asset held from time $(t-1)$ to time $t=5$ per cent

Therefore settlement on future at time $t, s_{t}$

$=\left(\mathrm{f}_{\mathrm{t}}-\mathrm{f}_{\mathrm{t}-1}\right)+\left(\mathrm{d}_{\mathrm{t}}-\mathrm{r}_{\mathrm{t}-1} \mathrm{f}_{\mathrm{t}-1}\right)$

$=(79.5-78)+(7.0-0.05(78))$

$=4.6$.

Therefore a payment of 4.6 is due from shorts to longs. This consists of two components: an "expectations" component, $\left(f_{t}-f_{t-1}\right)$, reflecting a risein the expected return from holding housing assets in perpetuity; a "dividend" component, $\left(d_{t}-r_{t-1} f_{t-1}\right)$, reflecting the higher income over the last period on the perpetual claim on housing as compared with the alternative asset.

One rather strange feature of the pricing of perpetual futures is that because there is no arbitrage process which relates the futures price to the cash market, the expectations component of the price can be subject to "rational bubbles", in which the price $f_{t}$ gradually increases or decreases to an extreme value. The daily settlement $s_{t}$ need not be unduly affected by such a movement in $f_{t}$, provided that the movement is at a steady rate. To see this, note that adding a term $x_{t}$ to the futures price, where $x_{t}$ is defined according to $x_{t}=\left(1+r_{t-1}\right) x_{t-1}$, has no effect on the settlement $\mathrm{s}_{\mathrm{t}}$. A Igebraically, if we let $\mathrm{s}_{\mathrm{t}}{ }^{*}$ be the daily settlement under this condition, then

$$
\begin{aligned}
\mathrm{s}_{\mathrm{t}}^{*} & =\left\{\mathrm{f}_{\mathrm{t}}^{*} \mathrm{f}_{\mathrm{t}-1}^{*}\right\}+\left\{\mathrm{d}_{\mathrm{t}}-\mathrm{r}_{\mathrm{t}-1} \mathrm{f}_{\mathrm{t}-1}{ }^{*}\right\} \\
& =\left\{\left(\mathrm{f}_{\mathrm{t}}+\left(1+\mathrm{r}_{\mathrm{t}-1}\right) \mathrm{x}_{\mathrm{t}-1}\right)-\left(\mathrm{f}_{\mathrm{t}-1}+\left(1+\mathrm{r}_{\mathrm{t}-2}\right) \mathrm{x}_{\mathrm{t}-2}\right\}\right. \\
& +\left\{\mathrm{d}_{\mathrm{t}}-\mathrm{r}_{\mathrm{t}-1}\left(\mathrm{f}_{\mathrm{t}-1}+\left(1+\mathrm{r}_{\mathrm{t}-2}\right) \mathrm{x}_{\mathrm{t}-2}\right)\right\} \\
& =\left\{\mathrm{f}_{\mathrm{t}}-\mathrm{f}_{\mathrm{t}-1}\right\}+\left\{\mathrm{d}_{\mathrm{t}}-\mathrm{r}_{\mathrm{t}-1} \mathrm{f}_{\mathrm{t}-1}\right\} \\
& +\left\{\left(1+\mathrm{r}_{\mathrm{t}-1}\right) \mathrm{x}_{\mathrm{t}-1}-\left(1+\mathrm{r}_{\mathrm{t}-2}\right) \mathrm{x}_{\mathrm{t}-2}-\mathrm{r}_{\mathrm{t}-1} \mathrm{x}_{\mathrm{t}-2}-\mathrm{r}_{\mathrm{t}-1} \mathrm{r}_{\mathrm{t}-2} \mathrm{x}_{\mathrm{t}-2}\right\} .
\end{aligned}
$$


Journal of

Property

Finance

7,3

52

By rewriting the first term in the third bracket as $\left(1+r_{t-1}\right)\left(1+r_{t-2}\right) x_{t-2}$, we can see that the terms in that bracket sum to zero. Therefore the daily settlement $\mathrm{s}_{\mathrm{t}}{ }^{*}$ is the same as the normal daily settlement $s_{t}$ before the addition of the arbitrary $x_{t}$ term.

The possibility of rational speculative bubbles may be of little practical importance, since it seems doubtful that the market could develop an expectation that the price will go off to infinity unwarranted by fundamentals. However, to ensure that the perpetual futures price provides reliable information about the present value of the stream of income $\mathrm{d}_{\mathrm{t}}$, some kind of price limits may be desirable. For example, the price of a perpetual futures contract should certainly not be allowed to become negative, and should probably be limited to some range determined by plausible "extreme values" for the stream of dividends $d_{t}$ (Shiller, 1993a, p. 45). (A s explained in A ppendix 2, the price of a perpetual future is expected to tend to track the cash price of this stream of dividends.)

A ppendix 2: The price of a perpetual future will tend to track the market value of the corresponding perpetual claim: an explanation

This explanation relies on the "law of one price" assumption: that is, that the value of any portfolio is equal to the arithmetical sum of the value of its components. The notation follows that in the section on perpetual claims and perpetual futures.

We first observe that the value which the market places at time $t$ on the settlement $s_{t+1}$ must bezero, since anyone can receive that settlement just by entering into a futures contract. Denoting expected present values (with discounting at the risk-free rate of interest) at timet by the operator EPV, we can write

$$
E P V\left[s_{t+1}=E P V\left[f_{t+1}-f_{t}\right]+E P V\left[d_{t+1}-r_{t} f_{t}\right]=0 .\right.
$$

Therefore

$E P V\left[f_{t+1}+d_{t+1}\right]=E P V\left[f_{t}\left(1+r_{t}\right)\right]$.

But EPV $\left[f_{t}\left(1+r_{t}\right)\right]$ is the expected present value of the futures price increased by the risk-free rate of interest, which must be equal to the current futures price.

$$
\text { So } f_{t}=E P V\left[f_{t+1}+d_{t+1}\right]
$$

that is, the futures price at timet is the expected present value at that time of the futures price at time $t+1$, plus the index income received at time $t+1$.

By repeating this argument, we can obtain a similar expression for the futures price at time $t+1, t+2, t+3 \ldots$ By recursive substitution repeated $k$ times, we can write

$$
f_{t}+\text { EPV }\left[d_{t+1}+d_{t+2}+\ldots+f_{t+k}\right] \text {. }
$$

If we assume that the expected present value of $f_{t+k}$ tends to zero as $k$ tends to infinity, the right hand side of this equation is the expected present value of an infinite stream of payments of income. This will be the price of the perpetual claim.

Hence we have shown that the price $f_{t}$ of the perpetual future will tend to track the price of the corresponding perpetual claim. However, this argument is not quite as conclusive as a noarbitrage condition, which implies certain convergence of a cash price and a futures price over the term of the contract. A $n$ investor who anticipates holding a perpetual future for period $k$ cannot be certain that the terminal futures price $f_{t+k}$ will be exactly equal to the terminal cash price, as he could with a future of fixed term of $k$; but he can expect it to be fairly close. 